Civil Engineering

Volume 168 Issue CE6

Manufacturing cement-based materials and building products via extrusion: from laboratory to factory Zhou and $\mathrm{Li}$

ice | proceedings
Proceedings of the Institution of Civil Engineers Civil Engineering 168 November 2015 Issue CE6 Pages 11-16 http://dx.doi.org/10.1680/cien.14.00065 Paper 1400065

Received 18/09/2014 Accepted 27/04/2015

Published online: 13/08/2015

Keywords: concrete technology \& manufacture/materials technology/sustainability

ICE Publishing: All rights reserved
隹

\title{
Manufacturing cement-based materials and building products via extrusion: from laboratory to factory
}

$1 \quad$ Xiangming Zhou BEng, MEng(Res), PhD, PGCert Senior Lecturer in Civil Engineering, Brunel University, Uxbridge, UK
2 Zongjin Li BEng, MSc, PhD, PE, MHKIE

Professor in Civil Engineering Materials, Hong Kong University of Science and Technology, Hong Kong
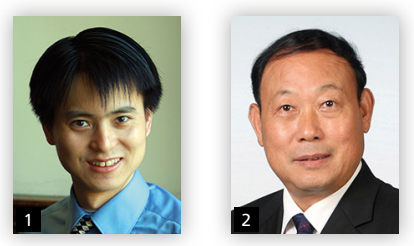

Manufacturing is critical to the economies of the UK and many other countries in the rest of the world. However, manufacturing of cement-based materials and building products predominantly remains based on old batch-processing techniques such as casting and pressing, and this may limit the applications and performance of the materials and products formed. This paper reports on research into transforming the manufacturing of precast cement-based materials and building products from in batches to continuous processes by way of extrusion. Techniques used for producing plastic products are transferred into manufacturing cement-based building products, such as flat and corrugated sheet tiles, downpipes, door and window frames, door panels, solid wall and facade panels, and honeycomb wall and facade panels, both at laboratory and factory scales. In combination with sustainable cementitious materials with low carbon dioxide emissions and low energy consumption as the matrix, this enables sustainable building products to be manufactured by way of extrusion.

\section{Introduction}

Manufacturing is critical to the economy of the UK and many other countries. Manufacturing directly accounts for $10 \%$ of the UK's gross domestic product and employs 2.5 million people, $9 \%$ of the employed labour force (Lavery et al., 2013). However, the UK manufacturing industry is facing rising labour, material and energy costs and tightening environmental restrictions.

The UK government is committed to reducing the country's greenhouse gas emissions by $80 \%$ compared with 1990 levels by 2050 . It is also committed to improving the capability and competitiveness of the manufacturing industry. Therefore, more efficient and greener manufacturing methods that can make significant contributions to the economy are urgently needed. Considering the huge volume of building products manufactured every year in the UK, a significant contribution to reaching national carbon dioxide emissions reduction targets could be achieved by enhancing the efficiency and sustainability of manufacturing methods for building products.

Cement-based materials are the most widely used construction materials and building products. However, their manufacture is predominantly based on old batch-processing techniques such as casting and pressing technologies, which limits the application and performance of the products formed. Batch processing is also labour and energy intensive.

Advanced manufacturing techniques could enhance material properties, reduce carbon dioxide emissions and energy consumption, generate less waste, make more efficient use of raw materials, generate additional profits and create new manufacturing jobs. Though the added value to a single unit may not be great, by considering the amount of Portland cement produced in the UK and in the world (10 Mt/y and $4 \mathrm{Gt} / \mathrm{y}$ respectively), the added economic, environmental and social benefits of advancing manufacturing techniques of cement-based materials and building products could be huge.

Many cement-based building products are reinforced with short discrete fibres. The performance of cementitious composites reinforced with short discontinuous fibres is comparable to that obtained with continuous aligned fibres or mats (Aldea et al., 1998). However, the fibre-cement industry is still using a traditional processing technique, the Hatschek process, which was invented more than 100 years ago. Since then, this process has been the main commercial production method for fibre-reinforced cementitious roofing and cladding products, and has undergone little change. 
Although the Hatschek method is a continuous process, composites made by this method are usually brittle ( $\mathrm{Li}$ and $\mathrm{Mu}$, 1998). The process generates a high level of wastewater and delamination of layers has been found in cement-based products made by this method during freeze-thaw cycles (Shao and Qiu, 2002). Products also exhibit a relatively high sorption and permeability (Shao and Qiu, 2002). An alternative processing method for fibre-cement building materials and products is thus needed - and extrusion could be the answer.

Extrusion is a commonly used material processing method throughout the ceramic, mechanical, chemical and pharmaceutical industries. This plastic-forming process consists of forcing a highly viscous, semi-solid, dough-like plastic mixture through a shaped die of desirable section. The process is continuous and simpler to use than many other conventional methods, and is therefore highly suited for industrial-scale mass production. Extrusion technology has begun to be employed by the fibre-cement industry as an alternative method for manufacturing high-performance fibre-cement building materials for traditional products such as bricks, tiles and pipes as well as advanced products such as honeycomb panels.

The advantage of introducing extrusion into fibre-cement products processing is that the materials are formed under high shear and compression during the extrusion process. This results in formed composites with improved performance. For the fibrecement manufacturing industry, the extrusion technique enables flexibility in fast fabrication of building products with regular or complicated shapes (e.g. finely structured honeycomb panels, window and door frames, and wave-shaped roof tiles) without the need for moulds, which can reduce labour costs and, consequently, production costs.

The semi-solid nature of the extruded materials means that the curing time for cement-based products can be significantly reduced. Qian et al. (2003) found that short discrete fibres can be aligned along the extrusion direction, so that the extrusion technique can also substantially improve the mechanical performance of fibre-cement composites and products. Extrusion can produce fibre-reinforced cement composites with a well-consolidated matrix and good fibre packing, resulting in low porosity and a strengthened fibre-matrix bond, which in turn leads to enhanced mechanical properties and durability (Peled and Shah, 2003; Teixeira et al., 2012).

\section{For the fibre-cement}

manufacturing industry, the extrusion technique enables flexibility in fast fabrication of building products with regular or complicated shapes (e.g. finely structured honeycomb panels, window and door frames, and waveshaped roof tiles) without the need for moulds
There are, however, disadvantages to employing extrusion in manufacturing fibre-cement materials and building products. Generally, the extrusion of fibre-cement materials requires compositional changes and relatively costly specialist processing additives, such as hydroxypropyl methylcellulose (Methocel, Dow Chemical Company), to facilitate extrusion. The degree of compaction in the extrusion process also decreases with increasing fibre content.

\section{Key factors to the extrusion of cement- based materials}

A successful and successive extrusion process largely depends on the rheology of the 'green' material during extrusion, the extrusion system and the interface between the green material and the extruder (including extruder screw, die-land and die-exit) during the process. Fresh cement-based materials suitable for extrusion (see Figure 1) exhibit semi-solid, dough-like rheological properties (Srinivasan et al., 1999) that are quite different from traditional fresh cement paste or mortar, which usually possesses a much higher water to cement ratio and flowability.

Cement-based dough-like fresh materials suitable for extrusion exhibit almost no fluidity but high cohesion under normal conditions. Only during extrusion are these fresh paste-like materials forced to flow in an extruder until being extruded out of the die-exit. Differing from polymeric materials that exhibit mainly viscous properties and become solid after being extruded out of the die-exit due to a phase change, cement-based dough-like materials tailored for extrusion exhibit coupled elastic, viscous and plastic rheological properties.

In the materials processing industry, rheological properties of materials are important for selecting processing conditions that enable a smooth extrusion process. However, it is not possible to use one single test to characterise the coupled elasto-visco-plastic rheological properties of cement-based materials tailored for extrusion (Zhou et al., 2013).

Alfani and Guerrini (2005) reviewed the most promising 'nontraditional' rheology test methods for concentrated and cohesive extrudable fresh cement-based materials and found that those 'promising' test methods were initially developed for materials such as plastics, rubber, clays, soils and metals, rather than traditional cement pastes or mortars with high flowability. Zhou et al. (2013)

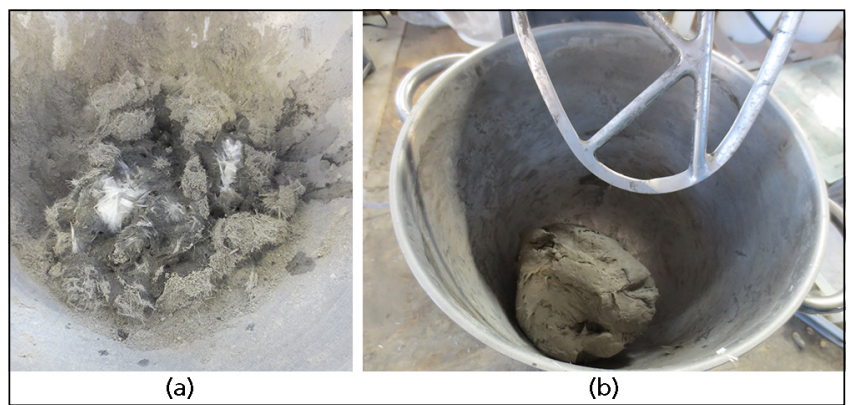

Figure 1. Semi-solid, dough-like fresh cement-based materials for extrusion: (a) during mixing not suitable for extrusion; (b) suitable for extrusion 
provide a summary of the non-traditional rheology test methods for semi-solid, dough-like fresh cement-based materials for extrusion, which include ram extrusion (Srinivasan et al., 1999; Zhou and Li, 2005a), capillary extrusion (Zhou and Li, 2005b), orifice extrusion (Zhou et al., 2013), upsetting and squeezing flow (Li and Li, 2007; Toutou et al., 2005; Zhou and Li, 2006).

An elasto-visco-plastic constitutive model was proposed by Zhou and Li (2011) for simulation of the coupled elasto-viscoplastic rheological properties of semi-solid, dough-like fresh cement-based materials for extrusion. The constitutive model was successfully employed in simulating the monotonic upsetting process (Zhou and $\mathrm{Li}, 2007$ ) and the ram extrusion process (Zhou and $\mathrm{Li}, 2009$ ) of semi-solid, dough-like fibre-reinforced fresh cement-based materials tailored for extrusion. On the other hand, Perrot et al. (2009) proposed linking the rheological concepts of firm cement-based materials and soil mechanics and established a simple criterion to predict the extrusion ability of a mortar.

Zhou and Rong (2014) employed a direct shear box test from soil mechanics and characterised the rheological properties of semi-solid, dough-like fresh fibre-cement composites for extrusion. The results were interpreted by a Mohr-Coulomb failure envelope. The effects of fibre volume and water content on the overall rheological properties of the materials for extrusion were characterised, which is helpful in selecting material compositions. They concluded that the direct shear box test is a simple but efficient test method for characterising the rheology of semi-solid, doughlike fresh cement-based materials for extrusion. Nevertheless, trialand-error is always helpful in tailoring material formulations.

Practically, ram extrusion is a simple but promising method that can give an indication of rheological properties and, most importantly, the extrudability of fibre-reinforced fresh cementbased paste-like materials. The ram extrusion mechanism is illustrated well by the Benbow-Bridgwater model, which is based on the assumption of plastic deformation in die-entry and plug flow in die-land. As schematically presented in Figure 2(a),

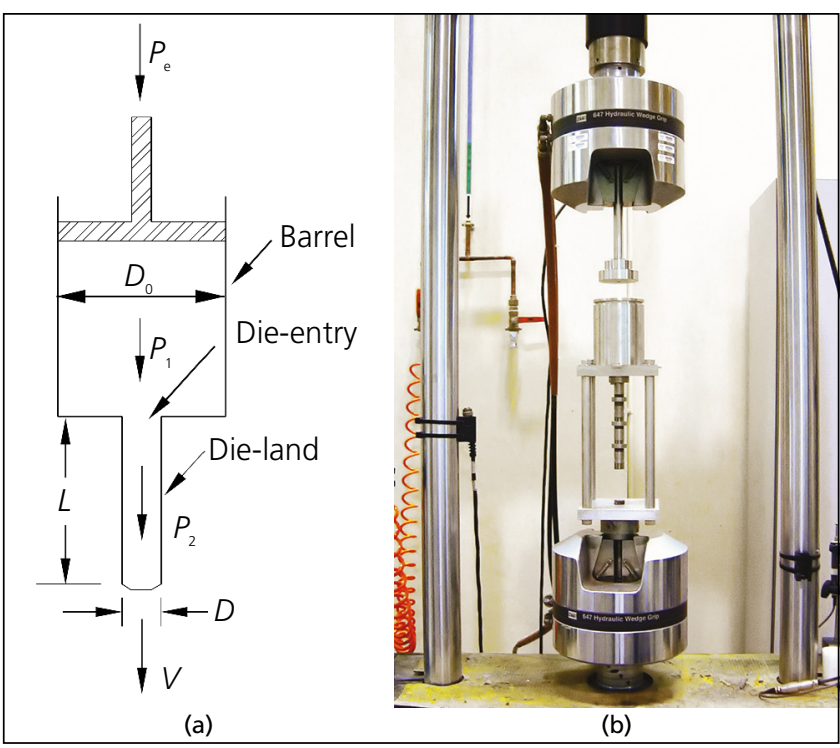

Figure 2. (a) Schematic illustration of ram extrusion. (b) Laboratoryscale ram extruder

\section{Practically, ram extrusion is a simple but promising method that can give an indication of rheological properties and, most importantly, the extrudability of fibre- reinforced fresh cement- based paste-like materials}

the total extrusion pressure drop $\left(P_{\mathrm{e}}\right)$ through a circular die with a die-entry angle of $90^{\circ}$ can be calculated by the equation proposed by Benbow and Bridgwater (1993).

Ram extruders can therefore be employed as a form of rheometer to provide a means of characterising the bulk and interfacial rheology of paste-like materials tailored for extrusion. The total extrusion pressure $P_{\mathrm{e}}$ at the upstream of material flow gives an indication of the rheological properties and extrudability of the semi-solid, dough-like material being processed. A higher pressure is required to extrude a stiffer paste-like material in ram extrusion. It can also be used to study the effect of individual compositions (e.g. binder, fibre and water contents) on the overall rheology and extrudability of the composite materials during extrusion.

Ram extrusion can also be employed to investigate the effects of the extrude-extruder interface on the extrudability of fibrecement fresh materials tailored for extrusion. A typical laboratoryscale ram extruder for tailoring the rheology and extrudability of fibre-cement dough-like fresh materials for extrusion is shown in Figure 2(b). Comprehensive studies on the effects of various compositions on overall rheology and extrudability of fresh cement-based materials for extrusion by way of ram extrusion have been presented by Srinivasan et al. (1999) and Zhou and Li (2005a), respectively. It should be noted, however, that the experience gained from ram extrusion cannot be directly applied to screw-based extrusion due to different materials flow in the two methods.

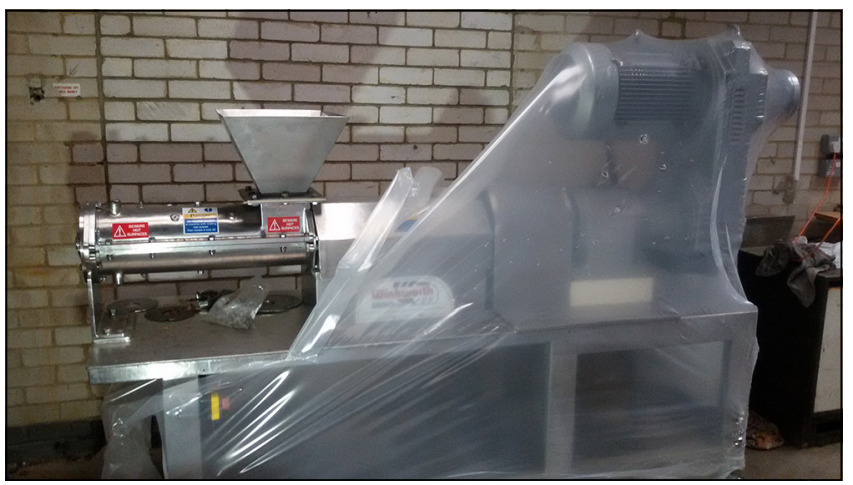

Figure 3. Screw extruder for pilot study of extrusion of fibre-cement building products 
Ram extrusion is an intermittent process, whereas screw-based extrusion can be a continuous process with raw materials fed at the upstream and products obtained at the downstream of the extrusion flow. Nevertheless, ram extrusion can be regarded as an indicator of the extrudability of materials and trial-and-error is always helpful in scaling up laboratory research to industrial production.

In a few laboratories around the world, various fibre-cement building products have been successfully produced, mainly by pilot-scale screw extruders (such as the one shown in Figure 3). These extruded building products include

- high-performance fibre-reinforced cementitious composite pipes (Stang and Pedersen, 1996)

- fibre-reinforced cement pressure pipes (Aldea et al., 1998)

- fibre-reinforced cement-based flat sheets (Li et al., 2001)

- cement-based lightweight and high-temperature-resistant flat sheets with perlite as aggregate ( $\mathrm{Li}$ et al., 2004)

- geopolymer composite building products (Li et al., 2005)

- nailable high-performance fibre-reinforced cement-based composites (Kuder and Shah, 2007)

- functionally graded fibre-reinforced cement composites (Shen et al., 2008)

- lightweight wood-magnesium oxychloride cement composite building products, which are also nailable and can be machined like wood (Figure 4) (Zhou and Li, 2012).
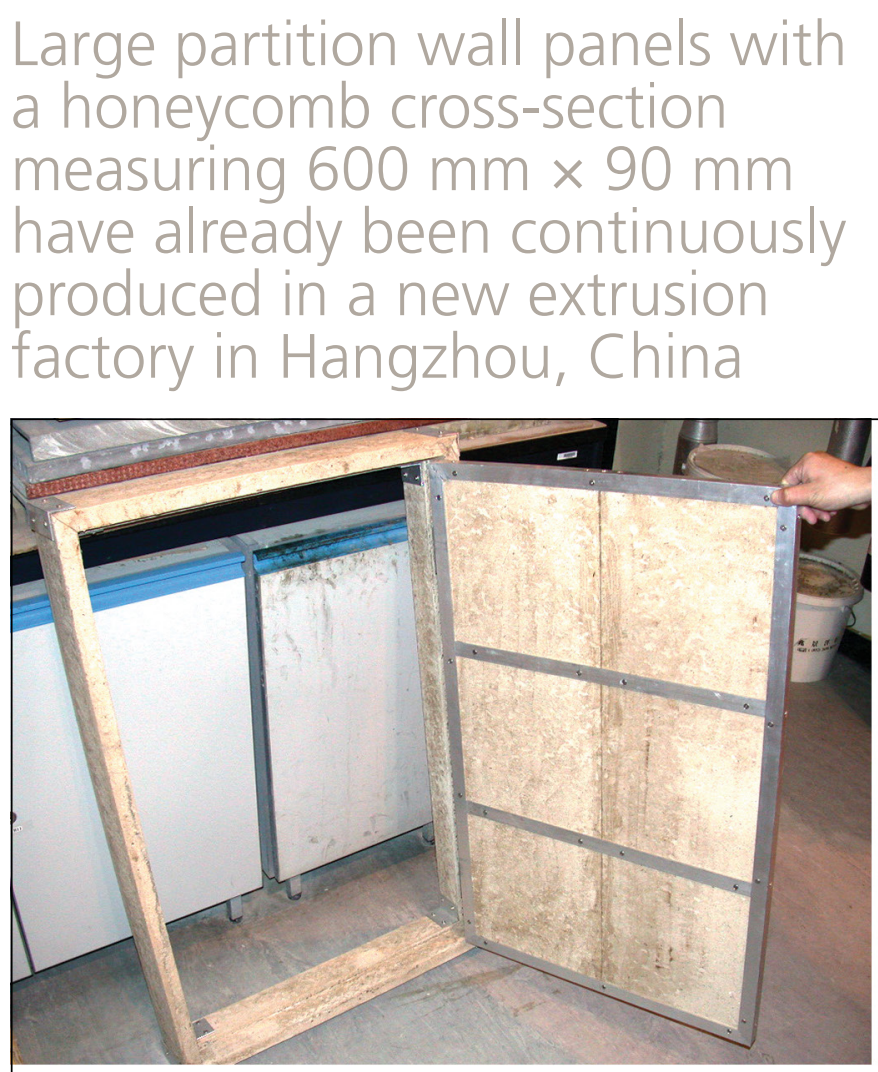

(a)
In addition, in the extruded building products, significant amounts of Portland cement were replaced by industry by-product supplementary cementitious materials (e.g. pulverised-fuel ash, ground granulated blast-furnace slag and metakaolin), which reduces embodied carbon dioxide and energy. The extrusion technique itself is regarded as a low-energy process. It is also a wet process, which can therefore reduce the troublesome issue of dust generation associated with the manufacture of cement-based products.

\section{Transformation of the extrusion technique to the fibre-cement industry}

The extrusion technique for manufacturing fibre-cement building products has recently been successfully applied in industry. A large extruder for processing fibre-cement composite building products has been invented (Figure 5) and a fibre-cement building products extrusion factory has been established in Hangzhou, China (Figure 6). Large partition wall panels with a honeycomb crosssection of dimensions $600 \mathrm{~mm} \times 90 \mathrm{~mm}$ (Figures 7 and Figure 8) have been continuously produced in the factory to serve the needs of infrastructure development (e.g. residential buildings, offices and hotels) in Hangzhou. The extruder can be used for manufacturing fibre-cement building products with other cross-sections by just changing the shape of the die, indicating the flexibility of the extrusion system itself.

The European Commission has funded the project 'Nanotechnology enhanced extruded fibre reinforced foam cement based environmentally friendly sandwich material for building applications' (FIBCEM project) through the seventh research framework programme. One of the objectives of this project is to develop extrusion techniques for the commercial production of fibrereinforced cement-based building products of various geometries, in particular roofing tiles and sidings. The project consortium consists of both research organisations and commercial enterprises, with the

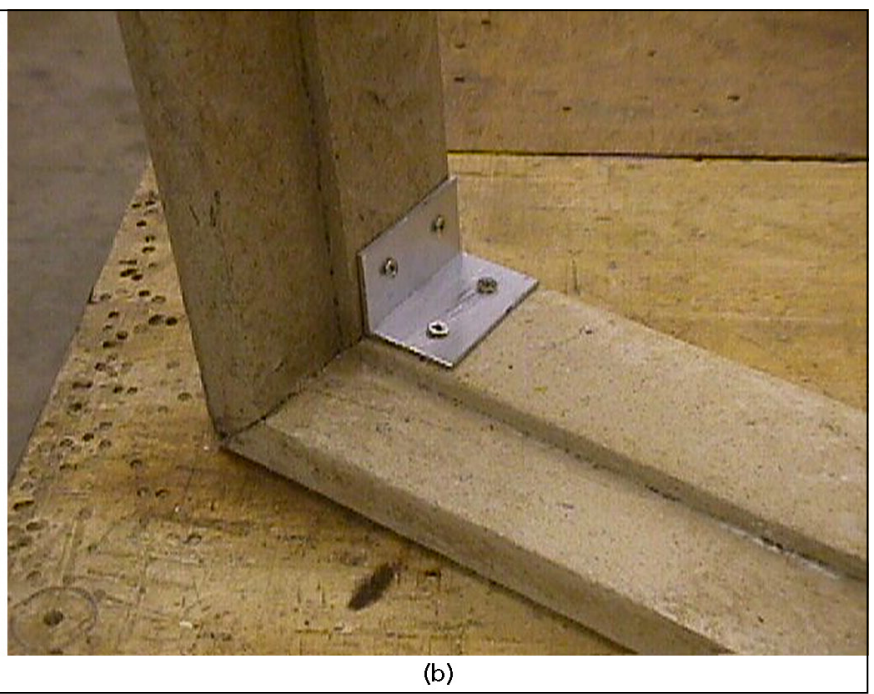

Figure 4. Extruded wood-magnesium oxychloride cement composites: (a) door frame and panels made of extruded products; (b) corner of the door with frames connected by angle steel and nails 
Civil Engineering

Volume 168 Issue CE6
Manufacturing cement-based materials and building products via extrusion: from laboratory to factory

Zhou and Li latter providing the knowledge and capability of creating economic and safe products based on the extrusion technology developed. It is expected that the extrusion technology developed in the FIBCEM project will be exploited by industry partners for commercial production of fibre-cement building products.

\section{Conclusions}

After two decades of research and development into extrusion techniques for the manufacture of cement-based materials and building products, the following conclusions can be drawn.

Firstly, extrusion is a promising materials processing technique for short discrete fibre-reinforced semi-solid, dough-like cementbased fresh materials to be used in the manufacture of building products.

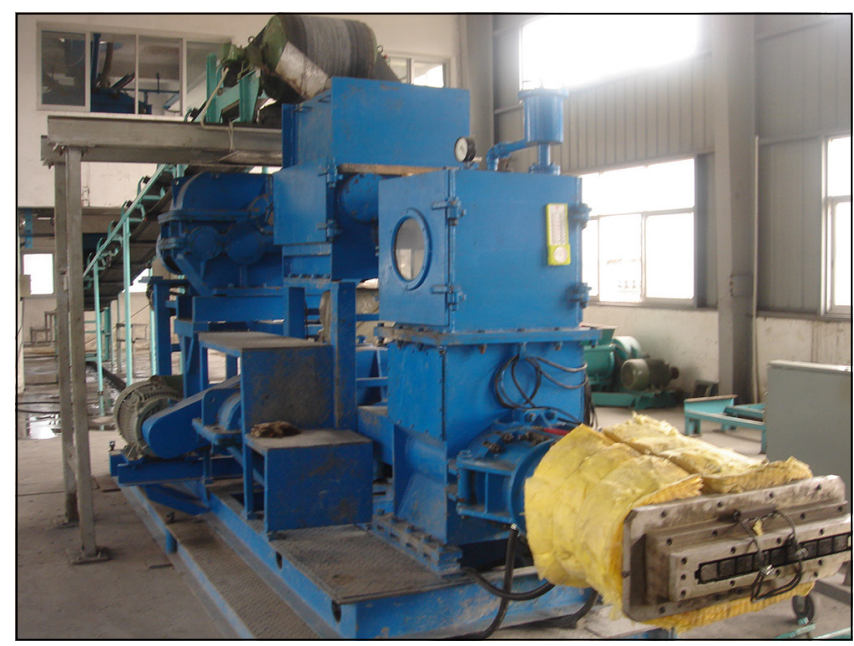

Figure 5. Factory-scale extruder for manufacturing fibre-cement building products

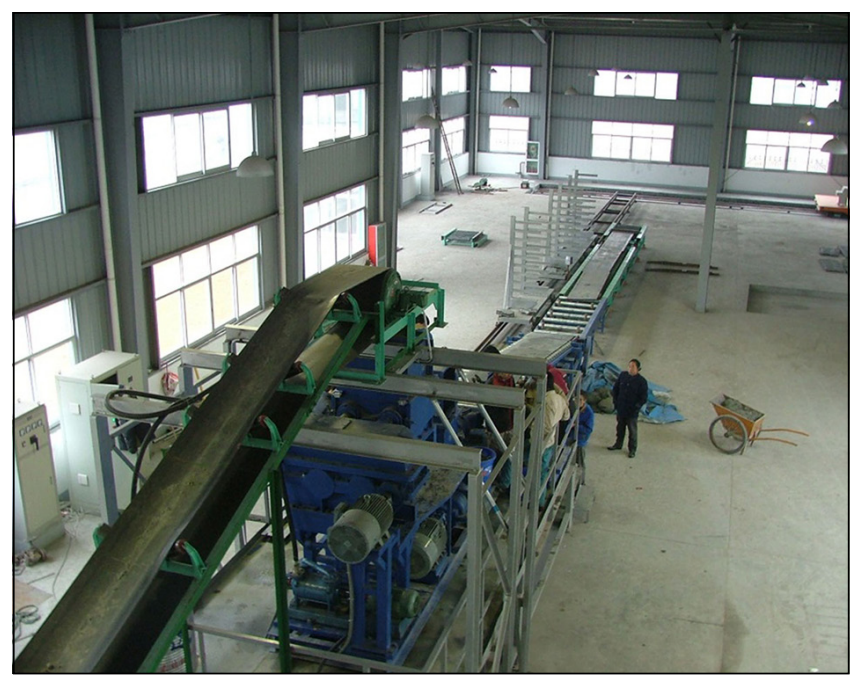

Figure 6. Overview of fibre-cement building products extrusion factory
The extrusion technique developed for manufacturing cement-based materials and building products has been validated in the laboratory and by pilot-scale production. It has also been scaled up for industrial mass production and has great potential in the construction industry

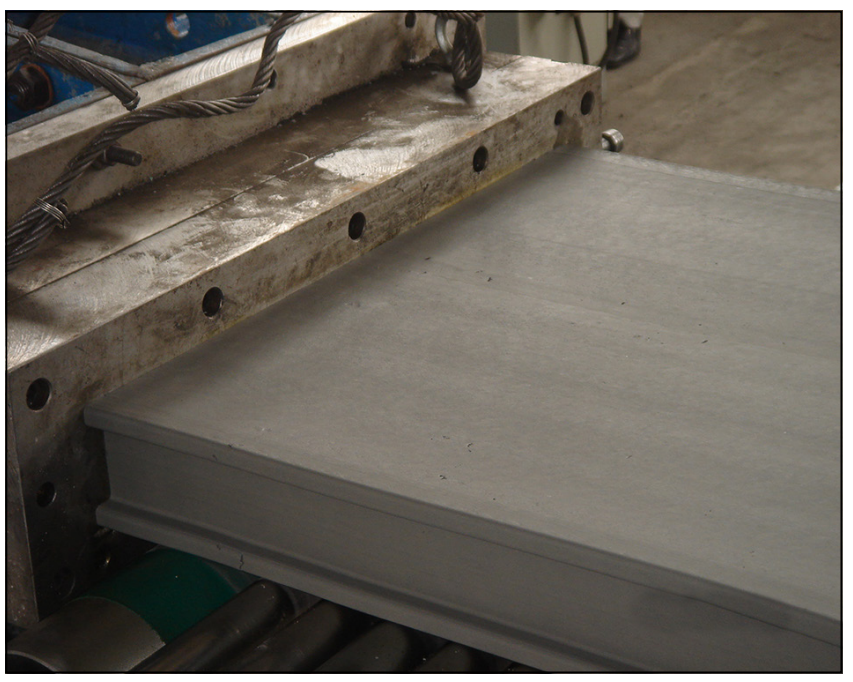

Figure 7. Fibre-cement extrudate just after die-exit

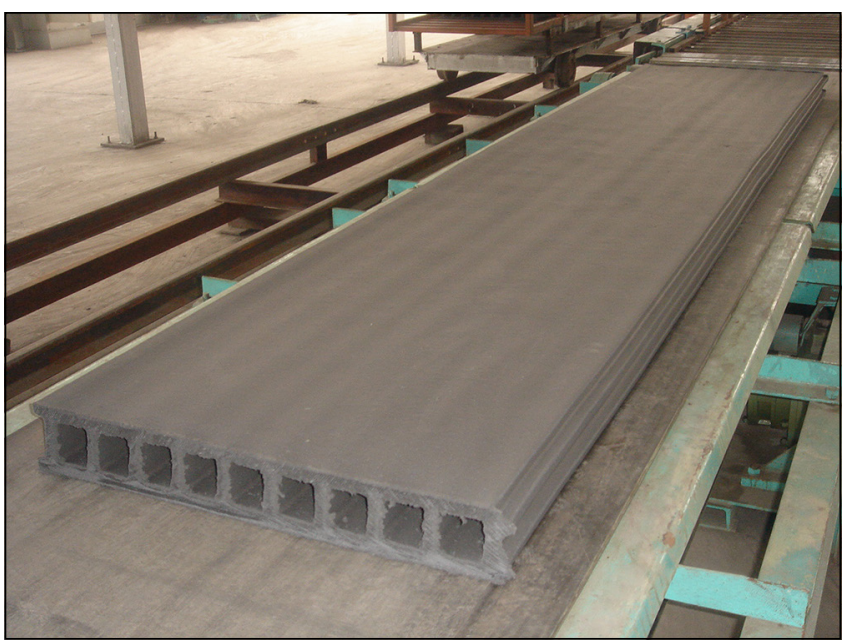

Figure 8. Extruded honeycomb fibre-cement partition wall panel of $600 \mathrm{~mm} \times 90 \mathrm{~mm}$ cross-section and several metres long 
Secondly, to achieve successive and successful extrusion of cement-based materials, appropriate rheological properties need to be attained and held during the process. Cement-based fresh materials suitable for extrusion exhibit coupled elastic, viscous and plastic rheological properties. Various test methods have been proposed for characterising the rheology of such semisolid, dough-like fibre-reinforced fresh cement-based materials for extrusion.

Thirdly, the extrusion technique developed for manufacturing cement-based materials and building products has been validated in the laboratory and by pilot-scale production. It has also been scaled up for industrial mass production. The extrusion of cementbased materials for manufacturing building products has great potential in the construction industry.

\section{Acknowledgements}

Partial financial support from the European Commission Seventh Framework Programme through the project 'Nanotechnology enhanced extruded fibre reinforced foam cement based environmentally friendly sandwich material for building applications' (FIBCEM) (grant agreement no. 262954) and from the Hong Kong Research Grants Council through grants 6091/00E, $6226 / 01 \mathrm{E}, 6273 / 03 \mathrm{E}$ and $6167 / 06 \mathrm{E}$ is gratefully acknowledged.

\section{References}

Aldea C, Marikunte S and Shah SP (1998) Extruded fiber reinforced cement pressure pipes. Advanced Cement Based Materials 8(2): 47-55.

Alfani R and Guerrini GL (2005) Rheological test methods for the characterisation of extrudable cement-based materials - a review. Materials and Structures 38(2): 239-247.

Benbow J and Bridgwater J (1993) Paste Flow and Extrusion. Clarendon Press, Oxford, UK

Kuder KG and Shah SP (2007) Tailoring extruded HPFRCC to be nailable. ACI Materials Journal 104(5): 526-534.

Lavery G, Pennell N, Brown S and Evans S (2013) The Next Manufacturing Revolution: Non-Labour Resource Productivity and its Potential for UK Manufacturing. See http://www.nextmanufacturingrevolution.org/wpcontent/uploads/2013/09/Next-Manufacturing-Revolution-full-report.pdf (accessed 01/06/2014).

Li ZJ and Li XY (2007) Squeeze flow of viscoplastic cement-based extrudate. Journal of Engineering Mechanics ASCE 133(9): 1003-1008.

Li ZJ and Mu B (1998) Application of extrusion for manufacture of short fibre-reinforced cementitious composite. Journal of Materials in Civil Engineering ASCE 10(1): 2-4.

Li ZJ, Mu B and Chui SNC (2001) Static and dynamic behaviour of extruded sheets with short fibers. Journal of Materials in Civil Engineering ASCE 13(4): 248-254.

Li ZJ, Zhou XM and Shen B (2004) Fiber-cement extrudates with perlite subjected to high temperatures. Journal of Materials in Civil Engineering ASCE 16(3): 221-229.

Li ZJ, Zhang YS and Zhou XM (2005) Short fiber-reinforced geopolymer composites manufactured by extrusion. Journal of Materials in Civil Engineering ASCE 17(6): 624-631.

Peled A and Shah SP (2003) Processing effects in cementitious composites: extrusion and casting. Journal of Materials in Civil Engineering ASCE 15(2): 192-199.
Perrot A, Rangeard D, Melinge Y, Estelle P and Lanos C (2009) Extrusion criterion for firm cement-based materials. Applied Rheology 19(5): 53042-53048.

Qian XQ, Zhou XM, Mu B and Li ZJ (2003) Fibre alignment and property direction dependency of FRC extrudate. Cement and Concrete Research 33(10): 1575-1581.

Shao Y and Qiu J (2002) The role of polymer additives in extrusion of fibercement composites. Proceedings of the 2nd Material Speciality Conference of the Canadian Society for Civil Engineering, Montreal, Canada. Canadian Society for Civil Engineering, Westmount, QC, Canada, pp. 1-8

Shen B, Hubler M, Paulino GH and Struble $\amalg$ (2008) Functionally-graded fiber-reinforced cement composites: processing, microstructure, and properties. Cement and Concrete Composites 30(8): 663-673.

Srinivasan R, DeFord D and Shah SP (1999) The use of extrusion rheometry in the development of extruded fibre-reinforced cement composites," Concrete Science and Engineering 1(1): 26-36.

Stang H, Pedersen C and Chong KP (eds) (1996) HPFRCC - extruded pipes. In Materials for the New Millennium. American Society of Civil Engineers, New York, NY, USA, pp. 261-270.

Teixeira RS, Tonoli GHD, Santos SF et al. (2012) Extruded cement based composites reinforced with sugar cane bagasse fibres. Key Engineering Materials 517: 450-457.

Toutou Z, Roussel N and Lanos C (2005) The squeeze test: a tool to identify firm cement-based material's rheological behaviour and evaluate their extrusion ability. Cement and Concrete Research 35(10) 1891-1899.

Zhou XM and Li Z (2005a) Characterisation of rheology of fresh fibrereinforced cementitious composites through ram extrusion. Materials and Structures 38(1): 17-24.

Zhou XM and Li ZJ (2005b) Characterising rheology of fresh short fibrereinforced cementitious composite through capillary extrusion. Journal of Materials in Civil Engineering ASCE 17(1): 28-35.

Zhou XM and Li ZJ (2006) Upsetting tests of fresh cementitious composites for extrusion. Journal of Engineering Mechanics ASCE 132(2): 149-157.

Zhou XM and Li ZJ (2007) Numerical simulations of upsetting process of the fresh fibre-cement paste. Journal of Engineering Mechanics ASCE 133(11): 1192-1199

Zhou XM and Li ZJ (2009) Numerical simulation of ram extrusion process of short fibre-reinforced fresh cementitious composite. Journal of Mechanics of Materials and Structures 4(10): 1755-1769.

Zhou XM and Li ZJ (2011) A constitutive model for fibre-reinforced extrudable fresh cementitious paste. Computers and Concrete $\mathbf{8 ( 4 )}$ : 371-388.

Zhou XM and Li ZJ (2012) Light-weight wood-magnesium oxychloride cement composite building products made by extrusion. Construction and Building Materials 27(1): 382-389.

Zhou XM and Rong H (2014) Characterisation of rheology of fresh cement-based materials for extrusion via direct shear test. Proceedings of 2nd International Conference on Advances in Civil, Structural and Environmental Engineering - ACSEE2014,Zurich, Switzerland, pp. 200-205.

Zhou XM, Li ZJ, Fan MZ and Chen HP (2013) Rheology of semi-solid fresh cement pastes and mortars in orifice extrusion. Cement and Concrete Composites 37: 304-311.

\section{What do you think?}

If you would like to comment on this paper, please email up to 200 words to the editor at journals@ice.org.uk. 